\title{
Compared effects of inhibition and exogenous administration of hydrogen sulphide in ischaemia-reperfusion injury
}

\author{
Khodor Issa ${ }^{1,2}$, Antoine Kimmoun 1,2,3, Solène Collin ${ }^{1,2,3}$, Frederique Ganster ${ }^{1}$, Sophie Fremont-Orlowski ${ }^{1,2,3}$, \\ Pierre Asfar ${ }^{4}$, Paul-Michel Mertes ${ }^{1,2,3}$ and Bruno Levy ${ }^{1,2,3^{*}}$
}

\begin{abstract}
Introduction: Haemorrhagic shock is associated with an inflammatory response consecutive to ischaemia-reperfusion (I/R) that leads to cardiovascular failure and organ injury. The role of and the timing of administration of hydrogen sulphide $\left(\mathrm{H}_{2} \mathrm{~S}\right)$ remain uncertain. Vascular effects of $\mathrm{H}_{2} \mathrm{~S}$ are mainly mediated through $\mathrm{K}^{+}{ }_{\text {ATP-channel activation. Herein, }}$ we compared the effects of $\mathrm{D}, \mathrm{L}-$-propargylglycine (PAG), an inhibitor of $\mathrm{H}_{2} \mathrm{~S}$ production, as well as sodium hydrosulphide (NaHS), an $\mathrm{H}_{2} \mathrm{~S}$ donor, on haemodynamics, vascular reactivity and cellular pathways in a rat model of I/R. We also compared the haemodynamic effects of $\mathrm{NaHS}$ administered before and 10 minutes after reperfusion.
\end{abstract}

Methods: Mechanically ventilated and instrumented rats were bled during 60 minutes in order to maintain mean arterial pressure at $40 \pm 2 \mathrm{mmHg}$. Ten minutes prior to retransfusion, rats randomly received either an intravenous bolus of NaHS $(0.2 \mathrm{mg} / \mathrm{kg})$ or vehicle $(0.9 \% \mathrm{NaCl})$ or PAG $(50 \mathrm{mg} / \mathrm{kg})$. PNU, a pore-forming receptor inhibitor of $\mathrm{K}^{+}{ }_{\text {ATP }}$ channels, was used to assess the role of $\mathrm{K}^{+}{ }_{\text {ATP }}$ channels.

Results: Shock and I/R induced a decrease in mean arterial pressure, lactic acidosis and ex vivo vascular hyporeactivity, which were attenuated by NaHS administered before reperfusion and PNU but not by PAG and NaHS administered 10 minutes after reperfusion. NaHS also prevented aortic inducible nitric oxide synthase expression and nitric oxide production while increasing Akt and endothelial nitric oxide synthase phosphorylation. NaHS reduced JNK activity and p-P38/P38 activation, suggesting a decrease in endothelial cell activation without variation in ERK phosphorylation. PNU + NaHS increased mean arterial pressure when compared with NaHS or PNU alone, suggesting a dual effect of NaHS on vascular reactivity.

Conclusion: NaHS when given before reperfusion protects against the effects of haemorrhage-induced I/R by acting primarily through a decrease in both proinflammatory cytokines and inducible nitric oxide synthase expression and an upregulation of the Akt/endothelial nitric oxide synthase pathway.

Keywords: hydrogen sulphide, inflammation mediators, therapeutic use, shock, hemorrhagic/drug therapy, haemodynamics/drug effects

\section{Introduction}

The reperfusion phase of haemorrhagic shock is associated with an inflammatory response, including increased NF$\kappa \mathrm{B}$ activation [1], increased inflammatory cytokine production [2], increased nitric oxide (NO) production and inducible nitric oxide synthase (iNOS) gene expression

\footnotetext{
* Correspondence: b.levy@chu-nancy.fr

'CHU Nancy, Groupe Choc Inserm, U961, Faculté de Médecine, 54511

Vandoeuvre les Nancy, France

Full list of author information is available at the end of the article
}

$[3,4]$, and increased activation of vascular $\mathrm{K}^{+}{ }_{\text {ATP }}$ channels. These inflammatory responses are associated with hypotension, vasodilation and hyporesponsiveness to vasopressor agents and lead to ischaemia-reperfusion (I/R) organ injury [5]. Treating and/or preventing I/R-induced organ injury is therefore a major challenge.

Hydrogen sulphide $\left(\mathrm{H}_{2} \mathrm{~S}\right)$ is recognised as a gasotransmitter, similar to $\mathrm{NO}$ and carbon monoxide. However, current knowledge relative to its role in physiology and pathology remains under discussion [6]. Many effects of

\section{Biomed Central}


$\mathrm{H}_{2} \mathrm{~S}$ are the subject of controversy [7]. Depending on the chosen models, $\mathrm{H}_{2} \mathrm{~S}$ has been reported to display opposite effects in haemorrhagic shock conditions. While inhaled $\mathrm{H}_{2} \mathrm{~S}$ and intravenous sodium sulphide and sodium hydrosulphide (NaHS) reportedly increased survival [8], improved haemodynamics, attenuated metabolic failure in rodents [9-11], exerted cardioprotective effects $[10,11]$ as well as protected against organ injury [12], sodium sulphide did not exert any beneficial effects in swine [13]. Moreover, in other studies, blocking $\mathrm{H}_{2} \mathrm{~S}$ biosynthesis with D,L-propargylglycine (PAG), a cystathionine $\gamma$-lyase inhibitor, improved haemodynamics and attenuated systemic inflammation and organ injury $[14,15]$.

The fact that $\mathrm{H}_{2} \mathrm{~S}$ injection was associated with an increase in arterial pressure is intriguing. Currently available data indicate that $\mathrm{H}_{2} \mathrm{~S}$ relaxes blood vessels [16] mostly, if not exclusively, by opening ATP-regulated potassium channels in vascular smooth muscle cells $[17,18]$. We hypothesised that $\mathrm{H}_{2} \mathrm{~S}$ injected at the time of reperfusion could decrease the consequences of shock and reperfusion, that the use of an inhibitor of endogenous $\mathrm{H}_{2} \mathrm{~S}$ production leads to opposite effects, and that adding a vascular $\mathrm{K}^{+}{ }_{\mathrm{ATP}}$-channel inhibitor would improve the effects of $\mathrm{H}_{2} \mathrm{~S}$ on systemic haemodynamics. Using a previously published model of $I / R$ induced by haemorrhagic shock, we thus compared the effects of $\mathrm{H}_{2} \mathrm{~S}$ and of its inhibition as well as of $\mathrm{K}^{+}{ }_{\text {ATP- }}^{-}$ channel inhibition on haemodynamics, vascular reactivity and cellular pathways.

\section{Materials and methods}

The study protocol was approved by the Nancy Institutional Committee on Animal Care and Use. The experiments were performed in conformity with the European legislation on the use of laboratory animals.

\section{Animals}

Adult male Wistar rats, weighing $325 \pm 15$ g, were housed under 12-hour light/dark cycles in the animal facility of the University of Nancy 1 (France).

\section{Surgical procedure}

Animals were anaesthetised with intraperitoneal pentobarbital (50 mg/kg body weight). Rats were placed on a homeothermic blanket system to maintain rectal temperature between 36.8 and $37.8^{\circ} \mathrm{C}$ for the duration of the experiment. After local anaesthesia with lidocaine $1 \%$ (AstraZeneca, Rueil-Malmaison, France\}), a tracheotomy was performed and animals were mechanically ventilated (Harvard Rodent 683 ventilator; Harvard Instruments, South Natick, MA, USA) throughout the experiment. The ventilator was set to maintain carbon dioxide partial pressure in the vicinity of $40 \mathrm{mmHg}$ and oxygen was added in order to maintain oxygen partial pressure above $100 \mathrm{mmHg}$. The left carotid artery was exposed and a $2.0 \mathrm{~mm}$ transit-time ultrasound flow probe (Transonic Systems Inc., Ithaca, NY, USA) was attached to the artery to continuously measure carotid blood flow (CBF).

Under local anaesthesia, the femoral artery was canulated in order to measure the mean arterial blood pressure (MAP) and heart rate (HR) on the one hand, and to induce haemorrhagic shock on the other. The homolateral femoral vein was canulated for retransfusion of withdrawn blood, for fluid replacement and for bolus infusion of either vehicle or drugs.

\section{Induction of haemorrhagic shock and protocol design}

Surgery was followed by a 20 -minute stabilisation period. Thereafter, haemorrhagic shock was induced by the graded withdrawal of blood from the femoral artery to a reservoir until MAP decreased to $40 \mathrm{mmHg}$ and maintained during 60 minutes by further blood withdrawal or reinfusion of shed blood. At 60 minutes, shed blood was retransfused via the venous line within 10 minutes. Animals were continuously monitored for HR, MAP and CBF during 300 minutes. Hydration was performed with a perfusion of $0.9 \% \mathrm{NaCl}$ at a rate of $1.2 \mathrm{ml} /$ hour.

At the end of the experiment, rats were sacrificed and blood samples were collected for arterial lactate measurement, centrifuged $\left(4,000 \mathrm{rpm}, 15\right.$ minutes, $\left.4^{\circ} \mathrm{C}\right)$ and plasma aliquoted and stored at $-80^{\circ} \mathrm{C}$ until biochemical analysis. Organs (aorta, heart and liver) were also collected and stored at $-80^{\circ} \mathrm{C}$ until biochemical analyses.

\section{Pharmacological modulation}

The dehydrated NaHS powder (anhydrous, 2 g; Alpha Aesar GmbH \& Co, Ward Hill, MA, USA) was dissolved in isotonic saline under argon gas bubbling until a concentration of $40 \mathrm{mM}$ was obtained and intravenously administered as a single bolus $(0.2 \mathrm{mg} / \mathrm{kg}$ body weight) 10 minutes before retransfusion or 10 minutes after the end of retransfusion (late NaHS). PNU-37883A (guanidine; 4-morpholinecarboximidine- $N$-1-adamantyl- $N$ cyclohexyl hydrochloride) (Sigma Aldrich, St Quentin Fallavier, France) was dissolved in a 1:1 mixture of dimethyl sulphoxide and intravenously administered as a bolus $(1.5 \mathrm{mg} / \mathrm{kg})$ followed by $1 \mathrm{mg} / \mathrm{kg} /$ hour. The inducible NO synthase inhibitor 1400W (Sigma Aldrich) was administered intraperitoneally $(20 \mathrm{mg} / \mathrm{kg})$ at $\mathrm{T} 0$.

\section{Study design}

Eight groups of eight rats were studied, namely: sham rats, haemorrhagic shocked rats, shock + PAG (CSE inhibitor)-treated rats $(50 \mathrm{mg} / \mathrm{kg})$, shock + NaHS-treated rats, shock + late NaHS-treated rats, shock + PNU37883A-treated rats, shock + PNU + NaHS-treated rats, and shock $+1400 \mathrm{~W}$-treated rats. 


\section{Monitoring and measurements}

Arterial blood gases were controlled after the stabilisation period, in order to establish mechanical ventilation. Measurements of blood gas and blood glucose were recorded at baseline ( $t=0$ minutes at the beginning of haemorrhagic shock) and at two critical periods, namely at the end of reperfusion ( $t=70$ minutes $)$ and at the end of the experiment $(t=300$ minutes $)$. MAP, HR, $\mathrm{CBF}$ and rectal temperature were recorded at baseline and every 10 minutes thereafter during the observation period.

Lactate concentrations were determined using an automated blood gas analyser (ABL5 Radiometer; Neuilly-Plaisance, France).

\section{Biochemical analyses}

Plasma levels of IL-6 and TNF $\alpha$ were measured in duplicate with the use of rat IL-6 and TNF $\alpha$ ELISA kits (Quantikine ELISA; R\&D Systems Europe, LILLE, France) according to the manufacturer's instructions. Results were expressed as picograms of the measured cytokine per millitre of plasma.

\section{Measurement of nitrite/nitrate}

$\mathrm{NO}_{2}{ }^{-}$and $\mathrm{NO}_{3}{ }^{-}$are the primary oxidised products of $\mathrm{NO}$ reacting with water, and therefore the total concentration of $\mathrm{NO}_{2}{ }^{-} / \mathrm{NO}_{3}{ }^{-}$in plasma was used as an indicator of $\mathrm{NO}$ production in vivo. Briefly, the nitrate in the supernatant was first reduced to nitrite by incubation with nitrate reductase $(10 \mathrm{U} / \mathrm{ml})$ and NADPH $(629.2 \mu \mathrm{g} / \mathrm{ml})$ at room temperature for 30 minutes. Thereafter, total nitrite concentration in the samples was measured by Griess reaction following the addition of $100 \mu \mathrm{l}$ Griess reagent to $100 \mu \mathrm{l}$ sample in a 96-well plate with a flat transparent bottom. The optical density at $550 \mathrm{~nm}$ was measured by an ELISA microplate reader and normalised with the optical density at $550 \mathrm{~nm}$ of standard saline solutions.

\section{RNA extraction and quantitative RT-PCR}

Primers for quantitative RT-PCR were obtained from Eurogentec (Angers, France). Total RNA extraction was carried out with the RNA Plus mini kit (Qiagen, Courtaboeuf Cedex, France) according to the manufacturer's instructions. Total RNA was reverse-transcribed to cDNA using the iScript One-Step RT-PCR Kit for Probes (Biorad, Marnes-la-Coquette, France). cDNA obtained from the RT reaction was subjected to quantitative PCR using iTaq Fast SYBR Green Supermix with ROX (Biorad, Marnes-laCoquette, France). The primer and concentrations were optimised according to the manufacturer's guidelines. Expression of, Kir6.1 mRNA and SUR2B mRNA were measured using iTaq Fast SYBR Green Supermix (Biorad).

The PCR reaction parameters were as follows: incubation at $50^{\circ} \mathrm{C}$ for 2 minutes, incubation at $95^{\circ} \mathrm{C}$ for
10 minutes, and thereafter 40 denaturation cycles at $95^{\circ} \mathrm{C}$ for 15 seconds and annealing and extension at $60^{\circ}$ $\mathrm{C}$ for 1 minute. Each sample was determined in duplicate. To determine the relative mRNA levels, a standard curve for each gene was created using RNA isolated from the haemorrhagic shock group. Isolated RNA was reverse-transcribed, and dilution series of cDNA ranging from $1 \mathrm{pg}$ to $10 \mathrm{ng}$ were subjected to real-time PCR. The obtained threshold cycle values were plotted against the dilution factor to create a standard curve. Relative mRNA levels in test samples were then calculated from the standard curve.

\section{Vascular reactivity}

For in vivo determination, basal and maximal MAP values obtained after administration of $1 \mu \mathrm{g} / \mathrm{kg}$ bolus of norepinephrine were recorded in the sham, haemorrhagic shock, haemorrhagic shock + PNU and haemorrhagic shock $+1400 \mathrm{~W}$ groups.

For ex vivo determination, aortic rings and small mesenteric arteries were carefully dissected and mounted on a wire myograph (Danish Myo Technology, Arhus, Denmark). The experiments were performed at $37^{\circ} \mathrm{C}$ in a physiological salt solution with the following composition: $\mathrm{NaCl} 119 \mathrm{mM}$; $\mathrm{KCl} 4.7 \mathrm{mM} ; \mathrm{NaHCO}_{3}$ $14.9 \mathrm{mM} ; \mathrm{MgSO}_{4} \cdot 7 \mathrm{H}_{2} \mathrm{O} 1.2 \mathrm{mM} ; \mathrm{CaCl}_{2} 2.5 \mathrm{mM}$; $\mathrm{KH}_{2} \mathrm{PO}_{4} 1.18 \mathrm{mM}$; glucose $5.5 \mathrm{mM}$, continuously bubbled with $95 \% \mathrm{O}_{2}$ and $5 \% \mathrm{CO}_{2}$.

After an equilibration period (at least 20 minutes) under optimal passive tension, two successive contractions in response to the combination of $\mathrm{KCl}$ depolarisation $(100 \mathrm{mM})$ and phenylephrine (PE) $(10 \mu \mathrm{M})$ (SigmaAldrich) were used in order to test the maximal contractile capacity of the vessels. After a 20-minute washout period, concentration-response curves to PE were elicited by cumulative administration of this vasoconstrictor agonist ( $1 \mathrm{nM}$ to $100 \mu \mathrm{M}$ ) in order to determine the same concentration producing an equal level of contraction in the different groups. To study endothelium-dependent relaxation, aortic rings with functional endothelium were precontracted with PE $(1 \mu \mathrm{M})$ and then exposed to increasing incremental concentrations of acetylcholine ( $1 \mathrm{nM}$ to $100 \mu \mathrm{M}$; Sigma, St Louis, MO, USA). The presence of functional endothelium was confirmed with acetylcholine $(1 \mu \mathrm{M})$, which elicited a relaxation superior to $50 \%$.

\section{Western blotting}

Aorta and small mesenteric arteries (200 to $230 \mu \mathrm{m}$ ) were homogenised and lysed. Proteins $(20 \mu \mathrm{g})$ were separated on $10 \%$ SDS-PAGE. Blots were probed with the following antibodies: anti-iNOS (BD Biosciences, San Jose, CA, USA), phosphorylated endothelial nitric oxide synthase (p-eNOS) (rabbit anti-rat eNOS, phosphorylated (ser1177); Cell Signaling Technology Saint Quentin 
Yvelines, France), phosphorylated-Akt (p-Akt) (rabbit anti-rat Akt, phosphorylated (ser473); Cell Signaling Technology), phospho-SAPK/JNK (mouse, anti-rat SAPK/JNK, phosphorylated (Thr183/Tyr185); Cell Signaling Technology), phospho-p38 mitogen-activated protein kinase (mouse, anti-rat p38 MAPK, phosphorylated (Thr180/Tyr182); Cell Signaling Technology), and phosphor-p44/42 MAPK (Erk1/2) (rabbit anti-rat p44/p42 MAPK, phosphorylated (Thr1202/Tyr204); Cell Signaling Technology). Proteins were transferred onto nitrocellulose membranes and probed with a monoclonal mouse anti- $\alpha$-Tubulin antibody (Sigma-Aldrich).

Bound antibodies were detected with a secondary peroxidase-conjugated anti-mouse IgG (Promega, Madison, WI, USA). The blots were visualised using an enhanced chemiluminescence system (ECL Plus; Amersham, GE Healthcare Europe, Velizy-Villacoublay, France).

\section{Statistical analyses}

Results are expressed as the median and interquartile range for $n$ experiments ( $n$ representing the number of animals). Difference between groups was tested using a Kruskal-Wallis test. When the relevant $F$ values were significant at the $5 \%$ level, further pairwise comparisons were performed using a Dunn's multiple comparison test. All statistics were performed with the Statview software (version 5.0 software; SAS Institute, Cary, NC, USA). $P<0.05$ was considered statistically significant.

\section{Results}

Model characterisation

Shock and I/R-induced hypotension, lactic acidosis and vascular hyporeactivity to norepinephrine

The HR, MAP and CBF remained stable throughout the experiment in the control group (Figure 1; see Additional file 1). In animals subjected to haemorrhagic shock and retransfusion, blood withdrawal significantly decreased the MAP, HR and CBF (Figure 1; see Additional file 1). Haemorrhagic shock was associated with a marked elevation in plasma lactate $(9 \times 2 \mathrm{mmol} / \mathrm{l})$ compared with the sham group $(2.1 \times 0.5 \mathrm{mmol} / \mathrm{l})$ (see Additional file 2$)$, while the increase in arterial pressure induced by a bolus of $1 \mu \mathrm{g} / \mathrm{kg}$ norepinephrine was significantly decreased $(P<$ $0.01)$ in the shock group compared with sham animals (Figure 2).

Ischaemia-reperfusion is associated with overexpression/ activation of iNOS and vascular $\mathrm{K}^{+}{ }_{\text {ATP }}$ and increased proinflammatory cytokines

IR-induced vascular hyporeactivity to a bolus of $1 \mu \mathrm{g} / \mathrm{kg}$ norepinephrine was completely restored following the administration of $1400 \mathrm{~W}$, a selective inhibitor of iNOS, as well as PNU-37883A, a pore-forming receptor inhibitor of $\mathrm{K}^{+}$ATP channels (Figure 2). I/R was associated with an increase in aortic and mesenteric protein expression
Kir6.1 and SUR2B (Table 1). Plasma nitrite/nitrate $\left(\mathrm{NO}_{x}\right), \mathrm{TNF} \alpha$ and IL-6 were also increased in shock-only rats $(P<0.05)$ (Figure 3$)$.

Hemodynamic effects of NaHS administered 10 minutes after the end of reperfusion

MAP, HR and CBF were not different when compared between the late NaHS group and animals subjected to haemorrhagic shock and retransfusion (Figure 4).

\section{Comparative effects of NaHS and PAG}

Hydrogen sulphide donor NaHS prevents I/R-induced hemodynamic and metabolic dysfunction while PAG, an inhibitor of endogenous $\mathrm{H}_{2} \mathrm{~S}$ production, has no effects

NaHS but not PAG significantly attenuated the drop in MAP induced by $\mathrm{I} / \mathrm{R}(P<0.05)$ (Figure 1 ) while $\mathrm{CBF}$ and HR (data not shown) remained unaffected (Figure 1). All animals treated with NaHS survived the haemorrhagic shock, while haemorrhagic shocked rats and PAG-treated rats had MAP $<40 \mathrm{mmHg}$ (which we considered equivalent to death) at the end of the experiment. Haemorrhagic shock-induced hyperlactataemia was attenuated by NaHS (HS-NaHS $5 \times 2.3 \mathrm{mmol} / \mathrm{l})(P<0.05)$ but was not modified with PAG $(P<0.05)$ (see Additional file 2). Compared with shock-only rats and shock + PAG rats, NaHS-treated animals had a significantly improved $\mathrm{pH}(P<0.05)$ at the end of the experiment $\left(\mathrm{T}_{150}\right)$ (see Additional file 2 ).

Sodium hydrosulphide improves vascular function in rat aortic and small mesenteric vessels

$\mathrm{PE}$ induced a dose-dependent increase in tension in aortic and small mesenteric vessels in control rats. In contrast, haemorrhagic shock blunted PE-stimulated contraction $(P<0.01)$, whereas NaHS significantly restored the maximal contractile capacity to control levels $(P<0.05)$ while PAG had no effect (Figure 5A). Acetylcholine produced a concentration-dependent relaxation of isolated aortic and small mesenteric vessels. Compared with the sham group, vascular responses to acetylcholine decreased in the aorta of shock-only rats $(P<0.05)$. The addition of NaHS improved vascular response to acetylcholine while the inhibitor PAG did not modify endothelial function (Figure 5B). Effect of NaHS on inflammatory mediators in haemorrhagic shock rats

Plasma nitrite/nitrate $\left(\mathrm{NO}_{x}\right), \mathrm{TNF} \alpha$ and IL-6, which were increased in shock-only, control rats $(P<0.05)$, decreased in NaHS-treated rats $(P<0.05)$ and increased in PAG-treated rats $(P<0.05)$ (Figure 3$)$.

NaHS restores the phosphorylated Akt-to-Akt ratio and phosphorylated eNOS-to-eNOS ratio, while reducing haemorrhagic shock-induced upregulation of iNOS expression

Expression levels of Akt and phosphorylated Akt (Akt Ser473 phosphorylation) as well as phosphorylated Aktto-Akt ratio were decreased in the aorta of shock-only 

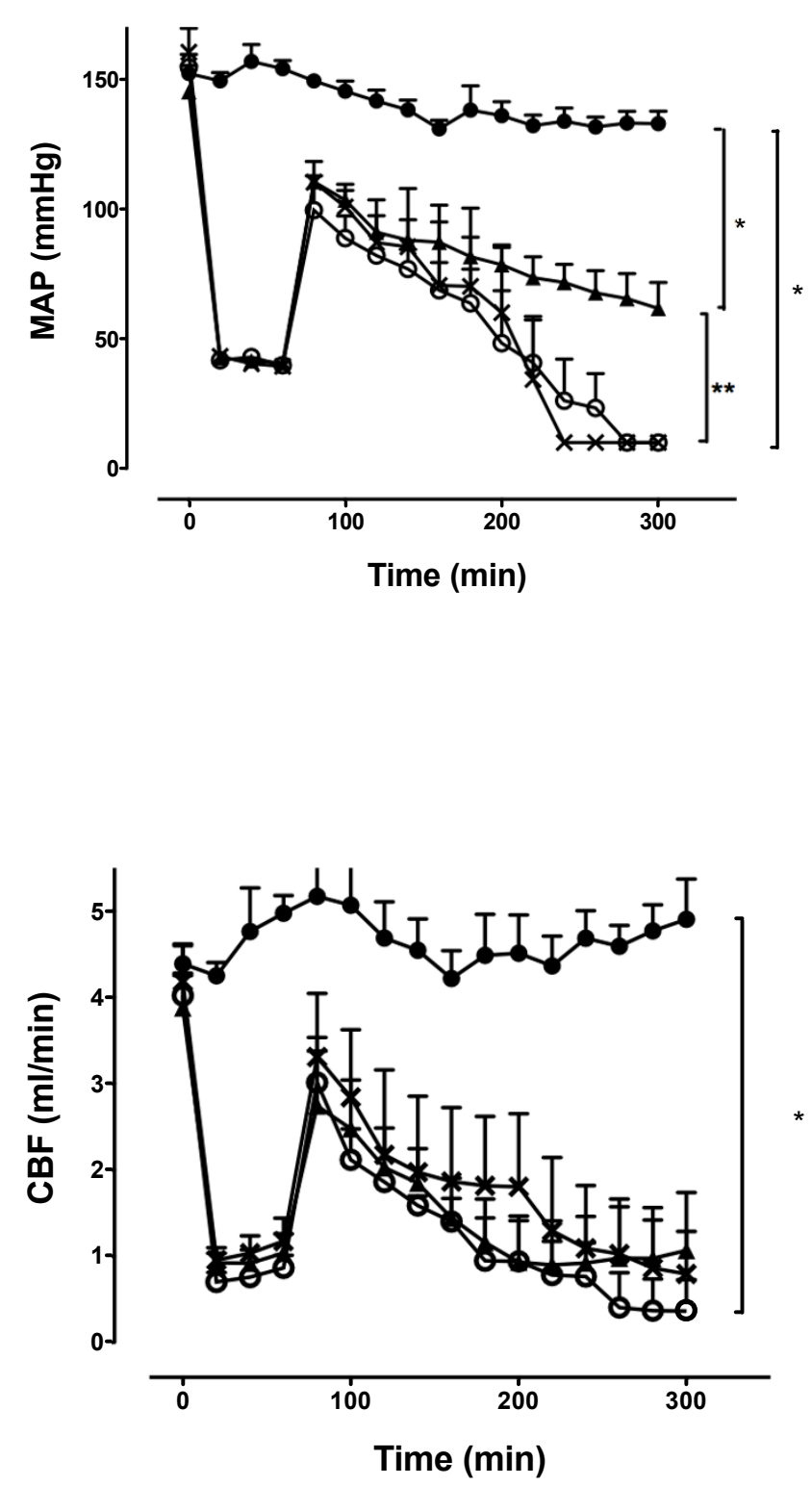

Figure 1 Hemodynamic measurements. (A) Mean arterial blood pressure (MAP) and (B) carotid blood flow (CBF) in the sham (filled circles), haemorrhagic shock + saline (crosses), haemorrhagic shock + sodium hydrosulphide (NaHS; triangles) and haemorrhagic shock + D, Lpropargylglycine (PAG; empty circles) groups recorded during a 300-minute monitoring period. ${ }^{*} P<0.05$, significantly different from sham. ${ }^{* *} P$ $<0.05$ versus haemorrhagic shock + NaHS group.

rats (Figure 6). NaHS treatment blunted this decrease while PAG rather increased their expression levels $(P<$ 0.05). Similar results were also found for phosphorylated eNOS-to-eNOS ratio

The expression of iNOS protein, as assessed by western blotting, increased in shock-only rats (compared with rats from the sham group). This increase in iNOS expression was significantly reduced following the administration of NaHS $(P<0.05)$ but increased with PAG $(P<0.05)$.
Effect of NaHS on alterations in p38 MAPK and JNK1/2 phosphorylation induced by haemorrhagic shock

NaHS reduced the phosphorylation of both p38 and JNK (Figure 6D,E). Conversely, PAG increased this phosphorylation compared with NaHS. Neither PAG nor NaHS influenced the phosphorylation of ERK (Figure 6F).

$P N U-37883 A$, a pore-forming receptor inhibitor of $\mathrm{K}^{+}{ }_{\text {ATP }}$ channels, further increases the effects of NaHS

PNU-NaHS was associated with a further increase in MAP when compared with NaHS alone $(P<0.05)$ (see 


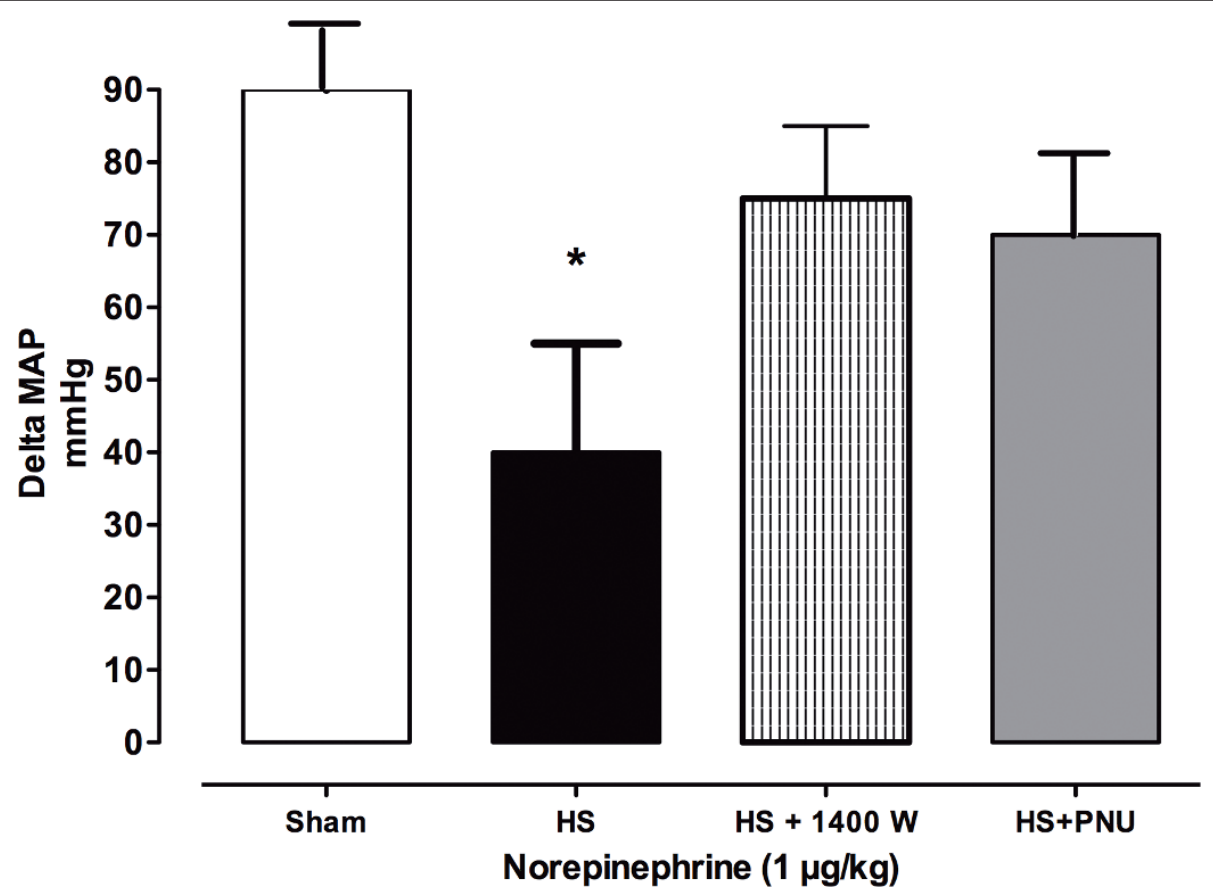

Figure 2 Mean arterial pressure after administration of norepinephrine. Mean arterial pressure (MAP) after administration of a bolus of $1 \mu \mathrm{g} / \mathrm{kg}$ norepinephrine in the haemorrhagic shock (HS) + saline, HS + 1400W (treated intraperitoneally with 1400W) and HS + PNU (treated with a 1-hour infusion of PNU-37883A; $1.5 \mathrm{mg} / \mathrm{kg}$ bolus followed by $1 \mathrm{mg} / \mathrm{kg} /$ hour) groups. ${ }^{*} P<0.05$, significantly different between HS + saline and all groups.

Additional file 3). PNU alone did not modify arterial $\mathrm{pH}$ nor the lactate level, whereas PNU-NaHS was associated with a decrease in lactate level and an increase in arterial $\mathrm{pH}$ as opposed to no differences with NaHS alone $(P<0.05)$ (data not shown).

\section{Discussion}

Herein, we illustrate the major role of NaHS in protecting the body against the consequences of shock and $I / R$ [19]. Our findings revealed that the pharmacological inhibition of the endogenous pathway of $\mathrm{H}_{2} \mathrm{~S}$ production during global I/R following a severe and reperfused haemorrhagic shock did not improve or worsen the consequences of shock, suggesting that endogenous $\mathrm{H}_{2} \mathrm{~S}$ production per se is an active protective mechanism during IR; and we confirm that NaHS, an exogenous donor of $\mathrm{H}_{2} \mathrm{~S}$, is beneficial in terms of haemodynamics, tissue

Table 1 mRNA expression of Kir6

\begin{tabular}{lll}
\hline & & Haemorrhagic shock \\
\hline Kir6.1 & Aorta & $21 \times 5^{*}$ \\
& Mesenteric & $7 \times 2^{*}$ \\
SUR2B & Aorta & $12 \times 7^{*}$ \\
& Mesenteric & $3 \times 0.3^{*}$ \\
\hline
\end{tabular}

$n=7$ in each group. ${ }^{*} P<0.05$, significantly different between haemorrhagic shock and sham groups. oxygenation and vascular reactivity. The effects of NaHS appear to be associated with a decrease in proinflammatory cytokines and a reduced expression of iNOS concomitant with a restoration of the eNOS pathway. These beneficial effects of NaHS appear to be more related to anti-inflammatory effects rather than to any specific vascular effect secondary to vascular $\mathrm{K}^{+}{ }_{\text {ATP }}$ activation since selective inhibition of vascular $\mathrm{K}^{+}{ }_{\text {ATP }}$ channels further improved haemodynamics and lactate metabolism in NaHS-treated rats. Furthermore, the effects of NaHS were not due to NaHS-induced hibernation since the animal's body temperature was continuously maintained. Finally, $\mathrm{H}_{2} \mathrm{~S}$ when given after reperfusion was not efficient.

Our model was characterised by profound and ultimately lethal hypotension, decreased blood flow, lactic acidosis and vascular hyporesponsiveness to vasopressor agents. These haemodynamic disturbances were associated with iNOS upregulation, proinflammatory cytokine production and activation/upregulation of vascular $\mathrm{K}^{+}{ }_{\text {AтP }}$ channels. The present findings confirmed that $\mathrm{H}_{2} \mathrm{~S}$ given prior to retransfusion limited the I/R-induced decrease in MAP without changing carotid blood flow and heart rate when compared with shock-only rats. Given that $\mathrm{H}_{2} \mathrm{~S}$ is usually considered an endogenous vasodilator acting through activation of vascular $\mathrm{K}^{+}{ }_{\text {ATP }}$, the role of this activation was further assessed with the 

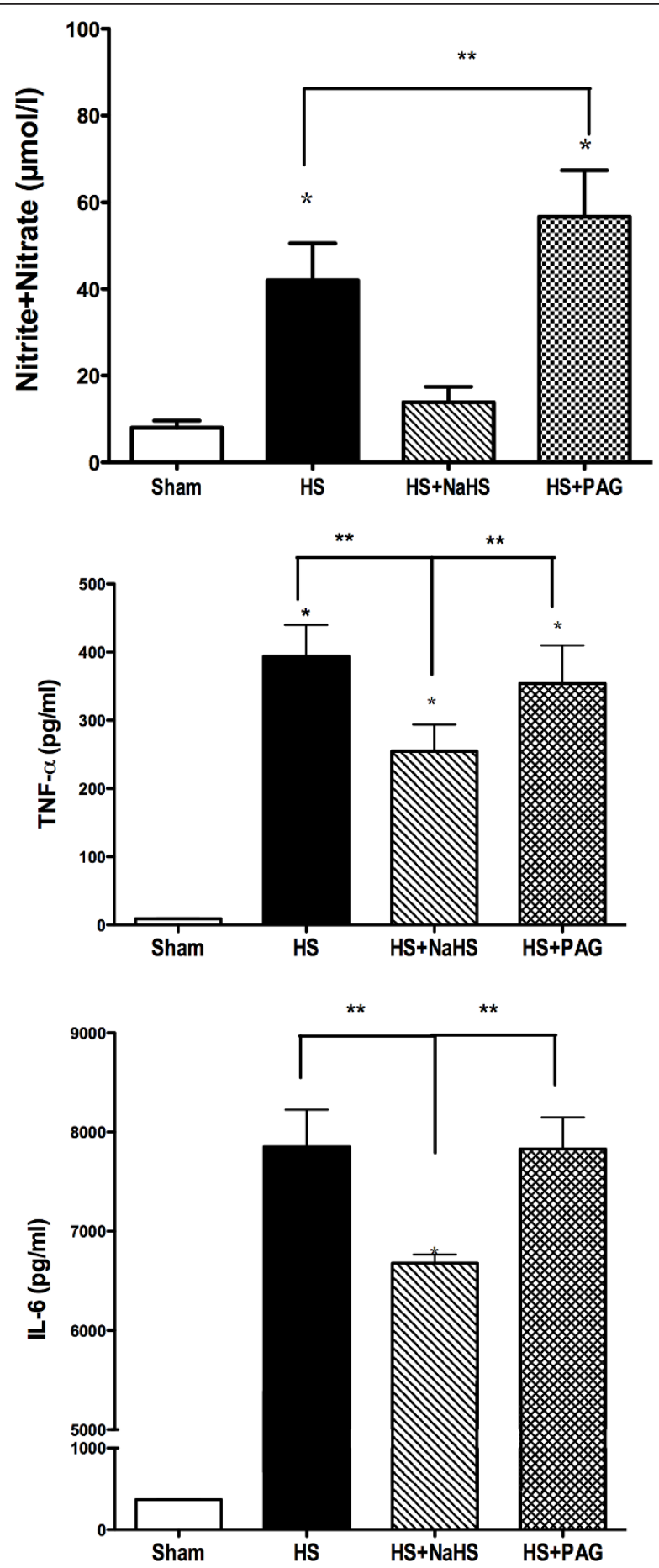

Figure 3 Effects of sodium hydrosulphide and d,l-propargylglycine. Effects of sodium hydrosulphide (NaHS) and D,L-propargylglycine (PAG) (50 mg/kg) on plasma levels of (A) nitrite + nitrate, (B) TNF $\alpha$ and (C) IL-6. Horizontal axes show the various groups. ${ }^{*} P<0.05$, significantly different between sham and all groups. ${ }^{*} P<0.05$ versus haemorrhagic shock $(\mathrm{HS})+\mathrm{NaHS}$ group.

selective vascular $\mathrm{K}^{+}{ }_{\text {ATP }}$ blocker, PNU-37883A. Our results first demonstrated that $\mathrm{K}^{+}$ATP channels were overactivated and overexpressed both at the gene and protein levels in this model, indicating that vascular $\mathrm{K}^{+}{ }_{\text {ATP }}$ is implicated in vascular hyporesponsiveness to vasopressor agents. Secondly, rats treated with $\mathrm{H}_{2} \mathrm{~S}+$ PNU exhibited a higher mean arterial pressure and a better vasoreactivity to norepinephrine. This may explain why $\mathrm{H}_{2} \mathrm{~S}$, which 

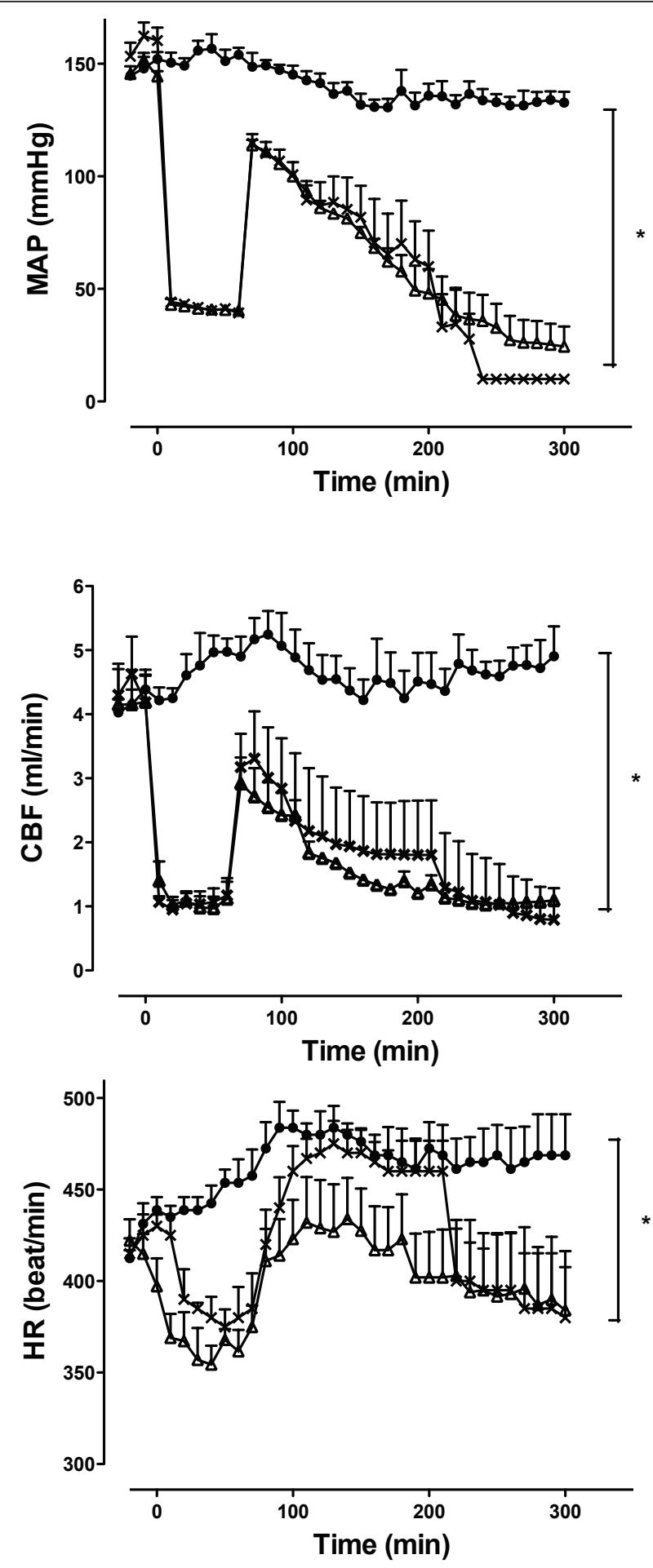

Figure 4 Hemodynamic measurements with sodium hydrosulphide administered 10 minutes after the end of reperfusion. Mean arterial blood pressure (MAP), carotid blood flow (CBF) and heart rate (HR) in sham (filled circles), haemorrhagic shock + saline (crosses), and haemorrhagic shock + sodium hydrosulphide $(\mathrm{NaHS})$ (triangles) groups recorded during a 300-minute monitoring period. ${ }^{*} P<0.05$, significantly between sham. 


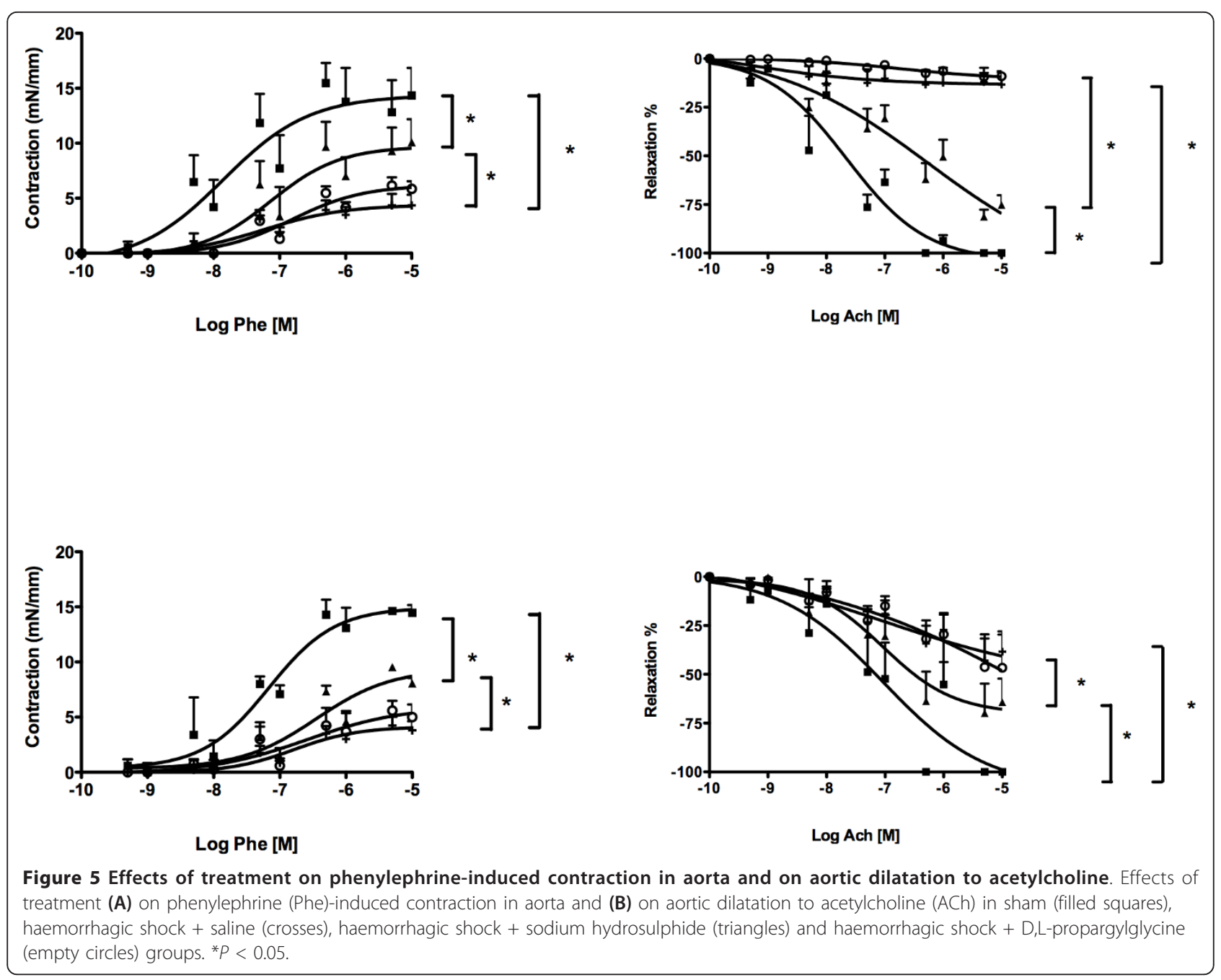

is generally regarded as an endogenous vasodilator, paradoxically increased MAP in this model. $\mathrm{H}_{2} \mathrm{~S}$ probably increases MAP through its well-demonstrated effects on the inflammatory pathway on the one hand, while decreasing MAP through $\mathrm{K}^{+}$ATP activation on the other, with the global result being an increase in MAP [20].

Potassium channels are critical metabolic sensors during acute metabolic changes such as hypoglycaemia or hyperglycaemia, ischaemia and hypoxia [21]. I/R-induced cardiovascular failure is traditionally ascribed to the effects of inflammatory mediators that induce circulatory changes with resulting tissue hypoxia and cell damage [22]. In the face of these deleterious signals, the body's adaptive response at the vascular level is to preserve cell survival through metabolic sensors by increasing local blood flow in the microcirculation, the so-called metabolic vasodilatation, in which the opening of $\mathrm{K}^{+}{ }_{\text {ATP }}$ channels plays a major role [23]. This adaptive response also leads to systemic vasodilatation, hypotension and potentially multiple organ failure and death. Vascular potassium channels may thus have protective but also harmful roles during shock. Therefore, while the use of channel inhibitors might be an attractive option to counteract systemic vasodilatation, it may also act as a double-edged sword. Whether $\mathrm{K}^{+}{ }_{\text {ATP }}$ activation is a protective phenomenon in this setting of disturbed microcirculation thus remains unknown.

\section{Hydrogen sulphide and PAG exert opposite effects on} pathways implicated in vascular failure

Ganster and colleagues demonstrated that $\mathrm{H}_{2} \mathrm{~S}$ improved cardiovascular status in $I / R$ by decreasing oxidative stress and inflammation through a decrease in NF- $\kappa \mathrm{B}$ activation [9]. Our present model was associated with an increase in proinflammatory and anti-inflammatory cytokines, an increase in iNOS expression and an alteration in eNOS phosphorylation. As for the phosphorylation pathway, JNK phosphorylation was increased without significant changes in the p-P38/P38 ratio. Indeed, JNK and P38 have been shown to be activated by TNF and IL-1 stimulation of endothelial cells [24] 


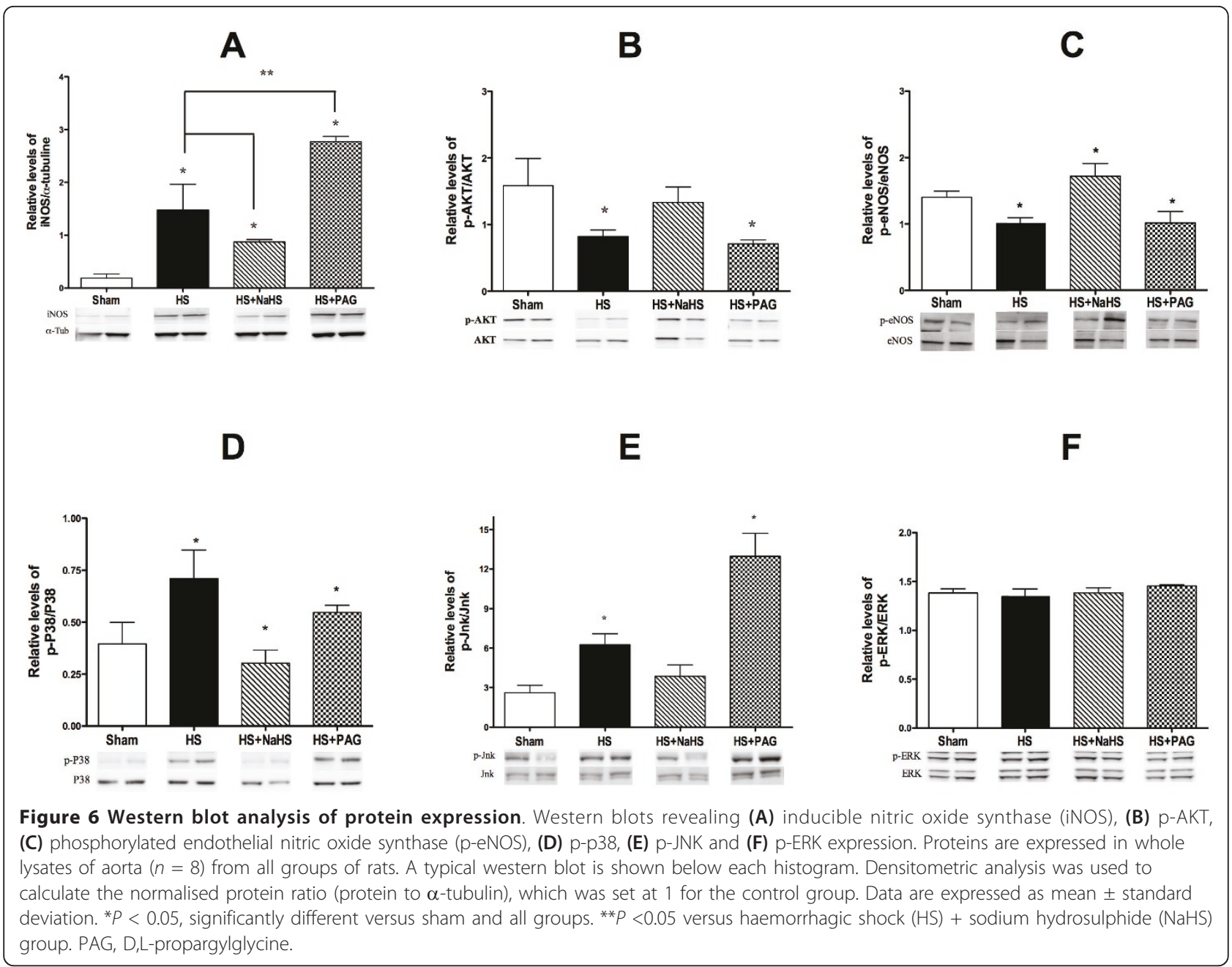

and to induce expression of proinflammatory effector molecules.

In the present study, $\mathrm{H}_{2} \mathrm{~S}$ was found to decrease the cytokine storm as well as both gene and protein iNOS expression while increasing Akt and eNOS phosphorylation. Moreover, $\mathrm{H}_{2} \mathrm{~S}$ reduced JNK activity and p-P38/ P38 activation, suggesting a decrease in endothelial cell activation [25]. Conversely, all of these parameters were either not altered or worsened with PAG injection.

\section{Study limitations}

The present model presents several limitations, first of which involves the use of a pressure-fixed and anaesthetised model of haemorrhagic shock that does not fully represent all of the specific patterns of human haemorrhagic shock.

Secondly, we used a fixed dose of NaHS that we previously found efficient without performing a dose-response study, thus leaving the possibility that potentially toxic or beneficial effects may have been missed.
Thirdly, we did not observe any differences between the shock group and the PAG-treated group with regard to haemodynamics, metabolism and proinflammatory cytokine parameters. Van de Louw and Haouzi recently demonstrated that, despite a severe cumulative oxygen debt (100 to $140 \mathrm{ml} / \mathrm{kg}$ ), $\mathrm{H}_{2} \mathrm{~S}$ blood and tissue concentrations did not change [26]. Nevertheless, despite the absence of a marked increase during $\mathrm{H}_{2} \mathrm{~S}$ treatment, blocking endogenous $\mathrm{H}_{2} \mathrm{~S}$ production most probably has little therapeutic benefit and may actually prove to be contraindicated [27].

Fourthly, when compared with mouse and humans, rats exhibited more iNOS activation during stress. The importance of the $\mathrm{H}_{2} \mathrm{~S}$-induced decrease in iNOS activation should therefore be discussed.

Lastly, the timing of $\mathrm{H}_{2} \mathrm{~S}$ administration might be discussed. While pretreatment with inhaled $\mathrm{H}_{2} \mathrm{~S}$ and intravenous sodium sulphide attenuated kidney, heart, and brain damage in mice undergoing $I / R$ injury or cardiac arrest $[28,29]$, similar post-treatment had no effect 
$[12,30]$. Our findings are in agreement with these previous reports suggesting that $\mathrm{H}_{2} \mathrm{~S}$ beneficial effects seem to be confined to a narrow timing window.

\section{Conclusion}

The present in vivo experimental study of $\mathrm{I} / \mathrm{R}$ following resuscitated haemorrhagic shock in rats demonstrates that $\mathrm{H}_{2} \mathrm{~S}$ administered exogenously before reperfusion is protective against the deleterious cardiovascular effects of haemorrhage-induced I/R. On the contrary, blocking endogenous $\mathrm{H}_{2} \mathrm{~S}$ production or administering $\mathrm{H}_{2} \mathrm{~S}$ after the reperfusion had no effect. More specifically, $\mathrm{H}_{2} \mathrm{~S}$ decreases proinflammatory cytokine and iNOS expression and restores the Akt/eNOS pathway. Such beneficial effects of $\mathrm{H}_{2} \mathrm{~S}$ donors warrant further experimental studies.

\section{Key messages}

- $\mathrm{H}_{2} \mathrm{~S}$, administered exogenously before reperfusion is protective against the deleterious cardiovascular effects of haemorrhage-induced I/R.

- $\mathrm{H}_{2} \mathrm{~S}$ is not effective when given after reperfusion.

- $\mathrm{H}_{2} \mathrm{~S}$ increased MAP through anti-inflammatory effects despite vasodilatory effects due to $\mathrm{K}^{+}{ }_{\text {ATP-channel }}$ activation.

- $\mathrm{H}_{2} \mathrm{~S}$ decreases proinflammatory cytokine and iNOS expression and restores the Akt/eNOS pathway.

\section{Additional material}

Additional file 1: Heart rate in sham (filled circles), haemorrhagic shock + saline (crosses), haemorrhagic shock + NaHS (triangles) and haemorrhagic shock + PAG (empty circles) groups recorded during a 300-minute monitoring period. ${ }^{*} P<0.05$.

Additional file 2: Metabolic parameters. Evolution of (A) lactate and (B) $\mathbf{p H}$. ${ }^{*} P<0.05$, significantly different versus sham group. ${ }^{*} P<0.05$ versus haemorrhagic shock $+\mathrm{NaHS}$ group.

Additional file 3: Hemodynamic measurements. MAP in the haemorrhagic shock + saline group (crosses), haemorrhagic shock + PNU (empty circles) group and haemorrhagic shock + PNU-NaHS (inversed triangles) rats recorded during a 300 -minute monitoring period. ${ }^{*} P<0.05$.

\begin{abstract}
Abbreviations
Akt: protein kinase B; CBF: carotid blood flow; ELISA: enzyme-linked immunosorbent assay; eNOS: endothelial nitric oxide synthase; ERK: extracellular signal-regulated kinases; $\mathrm{H}_{2} \mathrm{~S}$ : hydrogen sulphide; HR: heart rate; IL: interleukin; iNOS: inducible nitric oxide synthase; I/R: ischaemiareperfusion; JNK: c-Jun NH(2)-terminal protein kinases; $\mathrm{K}^{+}{ }_{\text {ATP: ATP-regulated }}$ potassium channels; MAP: mean arterial pressure; MAPK: mitogen-activated protein kinase; NaHS: sodium hydrosulphide; NF: nuclear factor; NO: nitric oxide; PAG: D,L-propargylglycine; PCR: polymerase chain reaction; PE: phenylephrine; PNU: 4-morpholinecarboximidine- $N$-1-adamantyl- $N^{\prime}$-cyclohexyl hydrochloride; p-P38/P38: phosphorylated/nonphosphorylated P38 kinase; RT: reverse transcriptase; TNF: tumour necrosis factor.
\end{abstract}

\section{Competing interests}

The authors declare that they have no competing interests.

\section{Authors' contributions}

$\mathrm{KI}$ participated in the study design, ran the experiments, performed the analysis and helped to draft the manuscript. SC and SF-O performed $\mathrm{K}_{\text {ATP }}^{+}$ RT-PCR and western blot. AK, FG, PA and P-MM participated in data analysis and helped to draft the manuscript. BL conceived the study and wrote the manuscript. All authors read and approved the final version of the manuscript.

\section{Authors' details}

${ }^{1}$ CHU Nancy, Groupe Choc Inserm, U961, Faculté de Médecine, 54511 Vandoeuvre les Nancy, France. 'Université de Lorraine, 54000 Nancy, France. ${ }^{3} \mathrm{CHU}$ Nancy, Service de Réanimation Médicale Brabois, Pole Cardiovasculaire et Réanimation Médicale, Hôpital Brabois, 54511 Vandoeuvre les Nancy, France. ${ }^{4}$ Laboratoire HIFI UPRES EA 3859, Université d'Angers, Angers, France.

Received: 5 February 2013 Revised: 16 April 2013

Accepted: 10 July 2013 Published: 10 July 2013

\section{References}

1. Altavilla D, Saitta A, Guarini S, Galeano M, Squadrito G, Cucinotta D, Santamaria LB, Mazzeo AT, Campo GM, Ferlito M, Minutoli L, Bazzani C, Bertolini A, Caputi AP, Squadrito F: Oxidative stress causes nuclear factorkappaB activation in acute hypovolemic hemorrhagic shock. Free Radic Biol Med 2001, 30:1055-1066.

2. Hierholzer C, Menezes JM, Ungeheuer A, Billiar TR, Tweardy DJ, Harbrecht BG: A nitric oxide scavenger protects against pulmonary inflammation following hemorrhagic shock. Shock 2002, 17:98-103.

3. Hua TC, Moochhala SM: Role of nitric oxide in hemorrhagic shockinduced bacterial translocation. J Surg Res 2000, 93:247-256.

4. Smail N CR, Wang P, Cioffi WG, Bland KI, Chaudry IH: Gut and liver: the organs responsible for increased nitric oxide production after traumahemorrhage and resuscitation. Arch Surg 1998, 133:399-405.

5. Md S, Moochhala SM, Siew Yang KL, Lu J, Anuar F, Mok P, Ng KC: The role of selective nitric oxide synthase inhibitor on nitric oxide and PGE2 levels in refractory hemorrhagic-shocked rats. J Surg Res 2005, 123:206-214.

6. Liu YH, Lu M, Hu LF, Wong PT, Webb GD, Bian JS: Hydrogen sulfide in the mammalian cardiovascular system. Antioxid Redox Signal 2012, 17:141-185.

7. Wagner F, Asfar P, Calzia E, Radermacher P, Szabo C: Bench-to-bedside review: hydrogen sulfide - the third gaseous transmitter: applications for critical care. Crit Care 2009, 13:213.

8. Morrison ML, Blackwood JE, Lockett SL, Iwata A, Winn RK, Roth MB: Surviving blood loss using hydrogen sulfide. J Trauma 2008, 65:183-188.

9. Ganster F, Burban M, de la Bourdonnaye M, Fizanne L, Douay O, Loufrani L, Mercat A, Cales P, Radermacher P, Henrion D, Asfar P, Meziani F: Effects of hydrogen sulfide on hemodynamics, inflammatory response and oxidative stress during resuscitated hemorrhagic shock in rats. Crit Care 2010, 14:R165.

10. Gao C, Xu DQ, Gao CJ, Ding Q, Yao LN, Li ZC, Chai W: An exogenous hydrogen sulphide donor, NaHS, inhibits the nuclear factor kappaB inhibitor kinase/nuclear factor kappab inhibitor/nuclear factor-kappaB signaling pathway and exerts cardioprotective effects in a rat hemorrhagic shock model. Biol Pharm Bull 2012, 35:1029-1034.

11. Chai W, Wang $Y$, Lin JY, Sun XD, Yao LN, Yang YH, Zhao H, Jiang W, Gao CJ, Ding Q: Exogenous hydrogen sulfide protects against traumatic hemorrhagic shock via attenuation of oxidative stress. J Surg Res 2012, 176:210-219.

12. Bracht H, Scheuerle A, Groger M, Hauser B, Matallo J, McCook O, Seifritz A, Wachter U, Vogt JA, Asfar P, Matejovic M, Moller P, Calzia E, Szabo C, Stahl W, Hoppe K, Stahl B, Lampl L, Georgieff M, Wagner F, Radermacher P, Simon F: Effects of intravenous sulfide during resuscitated porcine hemorrhagic shock. Crit Care Med 2012, 40:2157-2167.

13. Drabek T, Kochanek PM, Stezoski J, Wu X, Bayir H, Morhard RC, Stezoski SW, Tisherman SA: Intravenous hydrogen sulfide does not induce hypothermia or improve survival from hemorrhagic shock in pigs. Shock 2011, 35:67-73.

14. Mok YY, Moore PK: Hydrogen sulphide is pro-inflammatory in haemorrhagic shock. Inflamm Res 2008, 57:512-518.

15. Mok YY, Atan MS, Yoke Ping C, Zhong Jing W, Bhatia M, Moochhala S, Moore PK: Role of hydrogen sulphide in haemorrhagic shock in the rat: protective effect of inhibitors of hydrogen sulphide biosynthesis. $\mathrm{Br} J$ Pharmacol 2004, 143:881-889. 
16. Groeger M, Matallo J, McCook O, Wagner F, Wachter U, Bastian O, Gierer S, Reich V, Stahl B, M HL, Szabo C, Georgieff M, Radermacher P, Calzia E, Wagner K: Temperature and cell-type dependency of sulfide-effects on mitochondrial respiration. Shock 2012, 38:367-374.

17. Wang R: Signaling pathways for the vascular effects of hydrogen sulfide. Curr Opin Nephrol Hypertens 2011, 20:107-112.

18. Whiteman M, Moore PK: Hydrogen sulfide and the vasculature: a novel vasculoprotective entity and regulator of nitric oxide bioavailability? J Cell Mol Med 2009, 13:488-507.

19. Wagner F, Scheuerle A, Weber S, Stahl B, McCook O, Knoferl MW, HuberLang M, Seitz DH, Thomas J, Asfar P, Szabo C, Moller P, Gebhard F, Georgieff M, Calzia E, Radermacher P, Wagner K: Cardiopulmonary, histologic, and inflammatory effects of intravenous $\mathrm{Na} 2 \mathrm{~S}$ after blunt chest trauma-induced lung contusion in mice. J Trauma 2011, 71:1659-1667.

20. Wagner K, Georgieff M, Asfar P, Calzia E, Knoferl MW, Radermacher P: Of mice and men (and sheep, swine etc.): the intriguing hemodynamic and metabolic effects of hydrogen sulfide $\left(\mathrm{H}_{2} \mathrm{~S}\right)$. Crit Care 2011, 15:146.

21. Croker B, Crozat K, Berger M, Xia Y, Sovath S, Schaffer L, Eleftherianos I, Imler JL, Beutler B: ATP-sensitive potassium channels mediate survival during infection in mammals and insects. Nat Genet 2007, 39:1453-1460.

22. Annane D, Bellissant E, Cavaillon JM: Septic shock. Lancet 2005, 365:63-78.

23. Singer $M$, De Santis $V$, Vitale $D$, Jeffcoate W: Multiorgan failure is an adaptive, endocrine-mediated, metabolic response to overwhelming systemic inflammation. Lancet 2004, 364:545-548.

24. Surapisitchat J, Hoefen RJ, Pi X, Yoshizumi M, Yan C, Berk BC: Fluid shear stress inhibits TNF-alpha activation of JNK but not ERK1/2 or p38 in human umbilical vein endothelial cells: inhibitory crosstalk among MAPK family members. Proc Natl Acad Sci USA 2001, 98:6476-6481.

25. Keegan PM, Wilder CL, Platt MO: Tumor necrosis factor alpha stimulates cathepsin $\mathrm{K}$ and $\mathrm{V}$ activity via juxtacrine monocyte-endothelial cell signaling and JNK activation. Mol Cell Biochem 2012, 367:65-72.

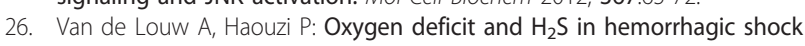
in rats. Crit Care 2012, 16:R178.

27. Calzia E, Radermacher $\mathrm{P}$, Olson KR: Endogenous $\mathrm{H}_{2} \mathrm{~S}$ in hemorrhagic shock: innocent bystander or central player? Crit Care 2012, 16:183.

28. Bos EM, Leuvenink HG, Snijder PM, Kloosterhuis NJ, Hillebrands JL, Leemans JC, Florquin S, van Goor H: Hydrogen sulfide-induced hypometabolism prevents renal ischemia/reperfusion injury. J Am Soc Nephrol 2009, 20:1901-1905.

29. Minamishima S, Bougaki M, Sips PY, Yu JD, Minamishima YA, Elrod JW Lefer DJ, Bloch KD, Ichinose F: Hydrogen sulfide improves survival after cardiac arrest and cardiopulmonary resuscitation via a nitric oxide synthase 3-dependent mechanism in mice. Circulation 2009, 120:888-896.

30. Wagner F, Wagner K, Weber S, Stahl B, Knoferl MW, Huber-Lang M, Seitz DH, Asfar P, Calzia E, Senftleben U, Gebhard F, Georgieff M, Radermacher $\mathrm{P}$, Hysa V: Inflammatory effects of hypothermia and inhaled H2S during resuscitated, hyperdynamic murine septic shock. Shock 2011, 35:396-402.

doi: $10.1186 /$ cc12808

Cite this article as: Issa et al:: Compared effects of inhibition and exogenous administration of hydrogen sulphide in ischaemiareperfusion injury. Critical Care 2013 17:R129.

\section{Submit your next manuscript to BioMed Central and take full advantage of:}

- Convenient online submission

- Thorough peer review

- No space constraints or color figure charges

- Immediate publication on acceptance

- Inclusion in PubMed, CAS, Scopus and Google Scholar

- Research which is freely available for redistribution 